Reprod. Nutr. Dévelop., 1986, 26 (1 B), 311-312.

\title{
Digestion du lactosérum dans le rumen chez les vaches laitières
}

\author{
B. RÉMOND, J. B. COULON
}

Laboratoire de la Lactation,

I.N.R.A. Theix, 63122 Ceyrat, France.

Summary. Feeding liquid whey to cows increased the concentrations of lactose, lactate and butyrate in the rumen while decreasing the $\mathrm{pH}$ and acetate concentration. These changes became more pronounced as intake and speed of consumption increased.

Les vaches laitières peuvent ingérer des quantités importantes de lactosérum (40 à 80 litres par jour ; Rémond et al., 1978). Cette ingestibilité élevée du lactosérum, sa haute fermentescibilité et son influence favorable sur le taux butyreux du lait nous ont incités à en étudier la digestion.

Matériel et méthodes. Nous avons utilisé 4 vaches équipées d'une canule du rumen, dont 2 l'étaient aussi d'une canule du duodénum. Elles ont d'abord reçu de l'ensilage de maïs complémenté en urée, à volonté, et de l'aliment concentré (à base de maïs grain) en fonction de leurs besoins, puis, au cours de 2 à 3 périodes successives de 2 à 4 semaines, 20, 40 ou 60 litres ( 2 vaches) ou 25 ou 50 litres (2 autres vaches) de lactosérum doux (MS \% $=5,84 ; \mathrm{pH}=6,20$ ) en remplacement d'une même quantité de matière sèche d'aliment concentré. Tous les aliments étaient distribués simultanément 2 fois par jour, sauf le lactosérum quand la ration journalière était de 20 litres. Au cours de chaque période expérimentale, des échantillons de jus de rumen ont été prélevés avant la distribution des aliments du matin et $1 \mathrm{~h}, 3 \mathrm{~h}$ et $7 \mathrm{~h}$ après, pendant 2 jours. On a mesuré leur $\mathrm{pH}$ et leurs teneurs en lactose et en acide lactique par voie enzymatique, et en acides gras volatils par chromatographie en phase gazeuse. La cinétique de l'ingestion du lactosérum a également été mesurée. La quantité totale de M.S. ingérée est passée de $14,8 \mathrm{~kg}$ en moyenne pour les 4 vaches pendant la $1^{\text {re }}$ période à $12,8 \mathrm{~kg}$ pendant la dernière période au cours de laquelle la quantité de lactosérum ingérée était de 40 litres, soit $18 \%$ (11 à $28 \%$ selon les vaches) de la M.S. totale.

Résultats et discussion. Les modifications de la digestion ont été d'autant plus importantes que la quantité de lactosérum ingérée et que sa vitesse d'ingestion étaient plus élevées (fig. 1). Le lactose n'a été dosé en quantité notable (jusqu'à $3 \mathrm{~g} / \mathrm{I}$ ) que dans les échantillons prélevés $1 \mathrm{~h}$ après la distribution des aliments. Dans les contenus de duodénum prélevés à 2 vaches aux mêmes heures que le jus de rumen, le lactose n'a été présent qu'à l'état de traces $(<0,05 \mathrm{~g} / \mathrm{l})$. Les teneurs les plus élevées en acide lactique ont généralement accompagné celles en lactose et ont entraîné des diminutions plus accentuées du $\mathrm{pH}$, qui n'est cependant jamais descendu au-dessous de 5,7 (vache 47). L'accroissement de la proportion de lactosérum a provoqué une augmentation de la proportion de l'acide butyrique dans les $A G V$ totaux (2,9 points pour une augmentation de 
10 points de la proportion de lactosérum; $P<0,01)$ aux dépens de celle de l'acide acétique $(-2,8$ points ; $P<0,01)$, celle de l'acide propionique ne variant pas. Ces effets, observés en moyenne pour les 4 prélèvements, ont été les plus importants $3 \mathrm{~h}$ et $7 \mathrm{~h}$ après la distribution des aliments. La concentration des AGV totaux n'a pas varié.

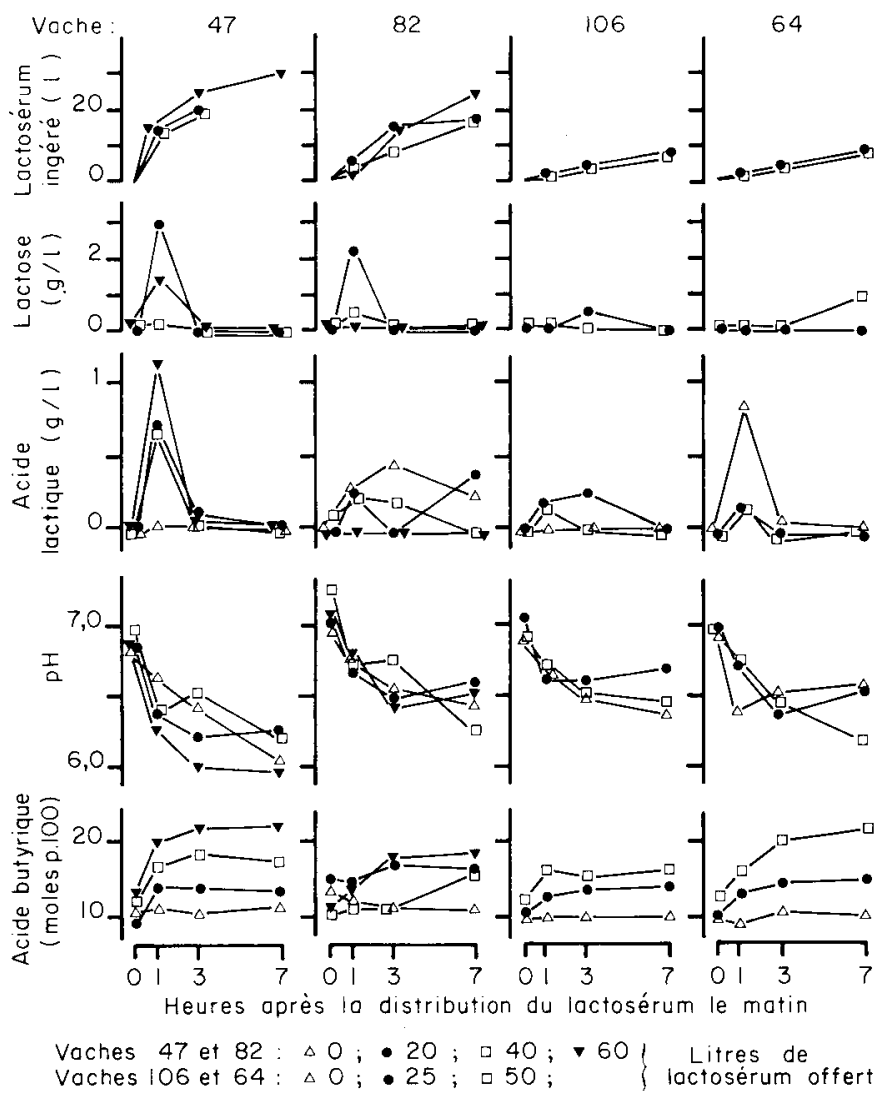

FIG. 1. - Evolution de l'ingestion de lactosérum et de quelques paramètres de la digestion dans le rumen (chaque point représente 1 ou 2 valeurs).

Nos résultats confirment ceux enregistrés par Thivend et Ehouinsou (1977) chez des moutons recevant du lactosérum déprotéinisé et déshydraté. Ils expliquent l'accroissement du taux butyreux du lait (Rémond et al., 1978) et montrent qu'avec cet aliment, la digestion est influencée par les quantités ingérées et par leur répartition, ce dont il faut tenir compte quand on veut l'incorporer au régime des animaux.

Rémond B., Marquis B., Hoden A., Journet M., 1978. Utilisation du lactosérum par les vaches laitières. Bull. Techn. C.R.Z.V. Theix, I.N.R.A., 33, 53-59.

Thivend P., Ehouinsou M. A., 1977. Digestion of lactose in the rumen of sheep. Proc. Nutr. Soc., 36, $73 \mathrm{~A}$. 